\title{
PENGARUH KUALITAS PELAYANAN KESEHATAN TERHADAP KEPUASAN PASIEN PESERTA BPJS DI RUMAH SAKIT UMUM DAERAH HAJI MAKASSAR
}

\section{THE EFFECT OF HEALTH SERVICE QUALITY ON SATISFACTION PATIENTS BPIS IN GENERAL HOSPITAL HAJI MAKASSAR}

\author{
Nirmayasri Datuan ${ }^{1}$, Darmawansyah ${ }^{2}$, Anwar Daud ${ }^{3}$ \\ ${ }^{1}$ Program Pascasarjana, Departmen Administrasi dan Kebijakan Kesehatan, Fakultas \\ Kesehatan Masyarakat, Universitas Hasanuddin \\ 2 Departmen Administrasi dan Kebijakan Kesehatan, Fakultas Kesehatan Masyarakat, \\ Universitas Hasanuddin \\ ${ }^{3}$ Departmen Kesehatan Lingkungan, Fakultas Kesehatan Masyarakat, Universitas \\ Hasanuddin
}

\begin{abstract}
Alamat Korespondensi: Nirmayasri Datuan, Fakultas Kesehatan Masyarakat, Universitas Hasanuddin, Makassar, 90242, HP: +6285298359186, Email: nirmadatuan09@gmail.com
\end{abstract}

\begin{abstract}
Abstrak
Kepuasan pasien adalah aspek penting dalam mengukur kualitas pelayanan kesehatan. Tujuan penelitian ini adalah untuk mengetahui pengaruh variabel keterjangkauan/ akses, kenyamanan, ketepatan waktu, terhadap kepuasan pasien peserta BPJS di RSUD Haji Makassar. Jenis penelitan yang dilakukan adalah penelitian kuantitatif dengan pendekatan cross sectional study. Populasi adalah pasien peserta BPJS di ruang rawat inap di RSUD Haji Makassar sebanyak 6369 pasien. Teknik pengambilan sampel pada penelitian ini menggunakan teknik accidental sampling dengan besar sampel 222 orang. Analisis data yang dilakukan adalah univariat dan bivariat dengan uji chi square, multivariat dengan uji regresi logistik. Hasil uji chi-square menunjukkan bahwa ada pengaruh keterjangkauan/ akses $(\mathrm{p}=0,039)$, ketepatan waktu $(\mathrm{p}=0,048)$, dan tidak ada pengaruh kenyamanan $(\mathrm{p}=0,725)$, terhadap kepuasan pasien peserta BPJS di ruang rawat inap di RSUD Haji Makassar Tahun 2018. Berdasarkan hasil uji regresi logistik variabel yang paling berpengaruh terhadap kepuasan pasien adalah keterjangkauan/ akses nilai $(\operatorname{Exp}(\mathrm{B})$ sebesar 2.128 kali nilai $\mathrm{p}=0,038)$. Diharapkan pada pihak rumah sakit agar dapat meningkatkan prasarana dan sarana pada unit perawatan RSUD Haji sehingga kepuasan pasien dapat meningkat.
\end{abstract}

Kata Kunci : Kualitas Pelayanan, Kepuasan pasien, BPJS

\begin{abstract}
Patient satisfaction is an important aspect in measuring the quality of health services. The purpose of this study is to determine the effect of affordability / access, convenience, timeliness, to the satisfaction of BPJS participants in RSUD Haji Makassar. Type of research conducted is quantitative research with cross sectional study approach. The population is the patient of BPJS participants in the inpatient room at Haji Makassar Hospital as many as 6369 patients. The sampling technique in this research used accidental sampling technique with 222 samples. The data analysis is univariate and bivariate with chi square test, multivariate with logistic regression test. The result of chi-square test shows that there is influence of access / accessibility $(p=0,039)$, punctuality $(p=0,048)$, and no influence of comfort $(p=0,725)$, to patient satisfaction of BPJS participant in inpatient room at Haji Makassar Year 2018. Based on the results of logistic regression test the most influential variable on patient satisfaction is affordability / access value $(\operatorname{Exp}(B)$ of 2,128 times the value $p=0.038)$. It is expected that the hospital to improve the infrastructure and facilities at Haji Makassar care unit so that patient's satisfaction can increase.
\end{abstract}

Keywords: Service Quality, Patient Satisfaction, BPJS 


\section{PENDAHULUAN}

Kepuasan penyelenggara (provider)

layanan kesehatan memang sangat penting, tetapi kepuasan itu sering terabaikan atau dilupakan. Pasien akan selalu mencari layanan kesehatan di fasilitas yang kinerja layanan kesehatannya dapat memenuhi harapan atau tidak mengecewakan pasien (Pohan, 2006). Kepuasan pasien merupakan salah satu indikator kualitas pelayanan yang diberikan dan kepuasan pasien adalah suatu modal untuk mendapatkan pasien lebih banyak dan untuk mendapatkan pasien yang loyal (Supriyanto, 2010).

\section{Konstitusi World Health}

Organization (WHO) berkomitmen untuk mengembangkan suatu sistem kesehatan dimana semua orang memiliki akses kepada pelayanan kesehatan yang diutuhkan tanpa terkendala biaya. Sistem kesehatan ini dikenal sebagai Universal Health Coverage (UHC). Untuk menghindari terjadinya kendala biaya, maka dikembangkan suatu sistem asuransi dalam upaya pencapaian UHC (WHO, 2011). Pada tahun 2004, dikeluarkan Undang- Undang No. 40 tentang Sistem Jaminan Sosial Nasional (SJSN). UndangUndang Nomor 40/ 2004 ini mengamanatkan bahwa jaminan sosial wajib bagi seluruh penduduk termasuk Jaminan Kesehatan Nasional (JKN) melalui suatu Badan Penyelenggara Jaminan Sosial. Undang -Undang No. 24
Tahun 2011 juga menetapkan Jaminan Kesehatan Nasional akan diselenggarakan oleh BPJS, yang terdiri atas BPJS Kesehatan dan BPJS Ketenagakerjaan. Khusus untuk Jaminan Kesehatan Nasional (JKN) akan diselenggarakan oleh BPJS Kesehatan yang implementasinya dimulai 1 Januari 2014 (Kemenkes RI, 2014).

Kepuasan pelanggan memiliki hubungan yang erat dengan kualitas. Kualitas memberikan suatu dorongan kepada pelanggan untuk menjalin ikatan hubungan yang kuat dengan perusahaan. Dalam jangka panjang, ikatan seperti ini memungkinkan perusahaan untuk memahami dengan seksama harapan dan kebutuhan pelanggan. Dengan demikian perusahaan dapat meningkatkan kepuasan pelanggan dengan cara memaksimumkan pengalaman yang menyenangkan dan meminimumkan atau meniadakan pengalaman pelanggan yang kurang menyenangkan (Tjiptono, 2006) .

Hal ini didukung oleh penelitian terdahulu yang menunjukkan bahwa aksebilitas, ketepatan waktu, hubungan antar manusia berpengaruh signifikan terhadap kepuasan pasien rawat inap (Karyanto, 2015). Penelitian yang dilakukan oleh Istiqnah menunjukkan bahwa secara keseluruhan pelayanan rawat jalan yang diterima pasien JKN di RS Universitas Hasanuddin, belum memuaskan dengan nilai gap sebesar -0,07 (Istiqna, 2015). 
Rumah Sakit Umum Daerah Haji

Makassar merupakan salah satu rumah sakit milik Pemerintah Provinsi Sulawesi Selatan dengan luas 1,06 hektar yang terletak di ujung selatan kota Makassar. RSUD Haji Makassar adalah salah satu rumah sakit tipe B. Indikator kinerja pelayanan RSUD Haji Makassar bahwa BOR (Bed Occupancy Ratio) pada tahun 2016 adalah 52\% serta pada tahun 2017 BOR adalah 50\%. Sedangkan Nilai Averange Lenght of Stay (AVLOS) pada tahun 2016 adalah 4 hari dan pada tahun 2017 nilai AVLOS adalah 3 hari. Jumlah kunjungan pasien rawat inap peserta BPJS di Rumah Sakit Umum Daerah Haji Makassar yang terdiri dari PBI dan non PBI pada tahun 2016 kunjungan pasien BPJS sebanyak 8.387, dan tahun 2017 mengalami penurunan menjadi 6.369. Data tersebut menunjukkan bahwa adanya penurunan persentasi BOR dari tahun 2016 sampai tahun 2017. Hal ini menyatakan bahwa nilai indikator efisiensi pemanfaatan tempat tidur di ruang rawat inap RSUD Haji Makassar belum mencapai target yakni 75-85 \% (Profil RSUD Haji Makassar, 2017).

Penurunan jumlah kunjungan pasien rawat inap di RSUD Haji Makassar menimbulkan pertanyaan apakah kualitas pelayanan yang diberikan belum memenuhi harapan pasien. Kualitas pelayanan yang tidak sesuai dengan harapan pasien, membuat tingkat kepuasan menjadi rendah, terutama bagi peserta BPJS PBI dan Non PBI yang secara mandiri membayar iuran untuk jaminan pelayanan kesehatan. Pengukuran kepuasan pelanggan merupakan elemen penting dalam menyediakan pelayanan yang lebih baik, efisien dan lebih efektif. Oleh karena itu, penelitian ini dilakukan untuk mengetahui kualitas pelayanan kesehatan dengan kepuasan pasien BPJS di unit rawat inap RSUD Haji Makassar.

\section{BAHAN DAN METODE}

\section{Lokasi dan Rancangan Penelitian}

Penelitian ini dilakukan di Rumah Sakit Umum Daerah Haji Makassar. Jenis penelitian yang digunakan dalam penelitian ini adalah penelitian kuantitatif dengan pendekatan cross sectional study.

\section{Populasi dan Sampel}

Populasi adalah seluruh pasien peserta BPJS yang ada di ruang rawat inap Rumah Sakit Umum Daerah Haji Makassar Tahun 2018. Besar sampel dalam penelitian ini adalah sebanyak 222 yang diperoleh dengan menggunakan metode accidental sampling.

\section{Metode Pengumpulan Data}

Pengumpulan data dilakukan dengan cara membagikan kuesioner kepada responden yang berisi pertanyaanpertanyaan. Data sekunder diperoleh dari dokumen-dokumen RSUD Haji Makassar. 


\section{Analisis Data}

Analisis data yang digunakan dalam penelitian ini adalah analisis univariat, analisis bivariat, analisis multivariat. Analisis univariat dilakukan untuk melihat karakteristik responden yang disajikan dengan tabel distribusi frekuensi. Analisis bivariat dilakukan untuk mengetahui pengaruh masingmasing variabel independen dan variabel dependen dengan menggunakan uji chi square. Analisis multivariatmenggunakan uji regresi logistik berganda, dilakukan untuk mengetahun variabel yang paling berpengaruh terhadap kepuasan pasien BPJS.

\section{HASIL}

\section{Karakteristik Responden}

Karakteristik responden berdasarkan umur, jenis kelamin, pendidikan, pekerjaan, status pernikahan dan jenis kepesertaan BPJS. Berdasarkan karakteristik umur, sebagian besar responden berumur antara 22-35 tahun sebanyak 92 (41,4\%) orang dibandingkan responden yang terendah antara 36-45 tahun sebanyak $35 \quad(15,8 \%)$ orang. Berdasarkan jenis kelamin sebagian besar responden adalah jenis kelamin perempuan sebanyak 133 responden perempuan $(59,9 \%)$ dan terdapat 89 responden lakilaki (40,1\%). Pendidikan terakhir responden yang terbanyak adalah berasal dari tingkat pendidikan tamat SMP sebanyak

67 responden $(30,2 \%)$ sedangkan yang terendah adalah tidak bersekolah sebanyak 2 responden ( 9\%). Dari segi pekerjaan menunjukkan bahwa sebagian besar responden dengan pekerjaan Ibu Rumah Tangga sebanyak 59 responden (26,6\%),sedangkan yang terendah adalah responden yang bekerja sebagai ABRI/POLRI sebanyak 2 responden $(0,9 \%)$. Status pernikahan menunjukkan bahwa responden yang paling banyak adalah responden dengan status menikah sebanyak 160 responden $(72,1 \%)$, sedangkan yang terendah adalah responden dengan status belum menikah sebanyak 60 responden (27,9\%). Berdasarkan status kepesertaan BPJS menunjukkan bahwa jumlah responden yang terbanyak adalah peserta BPJS PBI sebanyak 129 responden $(58,1 \%)$, sedangkan peserta BPJS Non PBI sebanyak 93 responden $(41,9 \%)$.

Tabel 1 menunjukkan bahwa berdasarkan keterjangkauan/ akses responden yang menyatakan keterjangkauan/ akses baik sebanyak 187 responden $(84,2 \%)$ dan kurang baik sebanyak 35 responden $(15,8 \%)$. Berdasarkan kenyamanan jumlah responden yang menyatakan kenyamanan baik 156 responden $(70,3 \%)$, dan terdapat 66 responden $(29,7 \%)$ menyatakan kurang baik .Dari segi ketepatan waktu responden yang menyatakan ketepatan waktu baik sebanyak 189 responden $(85,1 \%)$, dan 


\begin{tabular}{|c|c|c|c|c|}
\hline \multirow{15}{*}{$\begin{array}{l}\text { terdapat } \\
\text { Tabel 1: }\end{array}$} & 33 & responden & \multicolumn{2}{|c|}{ menyatakan kurang baik . } \\
\hline & \multicolumn{4}{|c|}{$\begin{array}{l}\text { Analisis Univariat Distribusi Responden Berdasarkan Keterj } \\
\text { Akses, Kenyamanan dan Ketepatan Waktu di Instalasi Rawa } \\
\text { Haji Makassar Tahun } 2018\end{array}$} \\
\hline & & Variables & $\mathrm{N}$ & $\%$ \\
\hline & & Keterjangkauan/ akses & & \\
\hline & & Baik & 187 & 84,2 \\
\hline & & Kurang Baik & 35 & 15,8 \\
\hline & & Total & 222 & 100 \\
\hline & & Kenyamanan & & \\
\hline & & Baik & 156 & 70,3 \\
\hline & & Kurang Baik & 66 & 29,7 \\
\hline & & Total & 222 & 100 \\
\hline & & Ketepatan waktu & & \\
\hline & & Baik & 189 & 85,1 \\
\hline & & Kurang Baik & 33 & 14,9 \\
\hline & & Total & 222 & 100 \\
\hline
\end{tabular}

Tabel 2: Analisis Bivariat Pengaruh Keterjangkauan/ Akses, Kenyamanan dan Ketepatan Waktu Terhadap Kepuasan Pasien Peserta BPJS di RSUD Haji Makassar Tahun 2018

\begin{tabular}{|c|c|c|c|c|c|c|c|}
\hline \multirow{3}{*}{ Variabel } & \multicolumn{4}{|c|}{ Kepuasan Pasien } & \multirow{2}{*}{\multicolumn{2}{|c|}{ Total }} & \multirow{3}{*}{$\begin{array}{l}\text { Hasil Uji } \\
\text { Statistik }\end{array}$} \\
\hline & \multicolumn{2}{|c|}{ Puas } & \multicolumn{2}{|c|}{ Kurang Puas } & & & \\
\hline & $\mathrm{N}$ & $\%$ & $\mathrm{n}$ & $\%$ & $\mathrm{n}$ & $\%$ & \\
\hline \multicolumn{8}{|c|}{ Keterjangkaun/ Akses } \\
\hline Baik & 169 & 86,6 & 22 & 13,4 & 187 & 100 & $p=0.039$ \\
\hline Kurang Baik & 31 & 97,1 & 4 & 2,9 & 35 & 100 & \\
\hline \multicolumn{8}{|l|}{ Kenyamanan } \\
\hline Baik & 139 & 89,1 & 17 & 10,9 & 156 & 100 & $p=0.725$ \\
\hline Kurang Baik & 57 & 86,4 & 9 & 13,6 & 66 & 100 & \\
\hline \multicolumn{8}{|c|}{ Ketepatan Waktu } \\
\hline Baik & 165 & 82,6 & 24 & 13,8 & 189 & 100 & $p=0.048$ \\
\hline Kurang Baik & 31 & 89,0 & 2 & 8,0 & 33 & 100 & \\
\hline
\end{tabular}

Tabel 2 menunjukkan bahwa dari total 187 responden yang menyatakan keterjangkauan/ akses baik, terdapat 165 orang $(86,6 \%) \quad$ diantaranya yang menyatakan merasa puas dengan rumah sakit dan 22 orang responden $(13,4 \%)$ yang merasa tidak puas. Sedangkan dari total 35 orang responden yang menyatakan keterjangkauan/akses kurang baik, terdapat 31 orang responden $(97,1 \%)$ yang merasa puas dengan pelayanan kesehatan dan 4 orang responden $(2,9 \%)$ yang merasa tidak puas. Hasil uji statistik dengan menggunakan uji chi-square diperoleh nilai $\mathrm{p}=0,039$, karena nilai $\mathrm{p}<0,05$ maka ada pengaruh keterjangkauan terhadap kepuasan pasien. 
Berdasarkan variabel kenyamanan, dari total 156 responden yang menyatakan kenyamanan baik, terdapat 139 orang (89,1\%) diantaranya yang menyatakan merasa puas dengan kenyamanan di rumah sakit dan 17 orang responden (10,9\%) yang merasa tidak puas. Sedangkan dari total 66 orang responden yang menyatakan kenyamanan kurang baik, terdapat 57 orang responden $(88,3 \%)$ yang merasa puas dengan pelayanan kesehatan dan 9 orang responden $(13,6 \%)$ yang merasa tidak puas. Hasil uji statistik dengan menggunakan uji chi-square diperoleh nilai $\mathrm{p}=0,725$ karena nilai $\mathrm{p}>0,05$ maka tidak ada pengaruh kenyamanan terhadap kepuasan pasien.
Tabel 2 meunjukkan bahwa dari total 189 responden yang menyatakan ketepatan waktu baik, terdapat 165 orang $(86,2 \%)$ diantaranya yang menyatakan merasa puas dengan ketepatan waktu pelayanan di rumah sakit dan 24 orang responden $(13,8 \%)$ yang merasa tidak puas. Sedangkan dari total 33 orang responden yang menyatakan ketepatan waktu kurang baik, terdapat 31 orang responden $(92,0 \%)$ yang merasa puas dengan pelayanan kesehatan dan 2 orang responden $(8,0 \%)$ yang merasa tidak puas. Hasil uji statistik dengan menggunakan uji chi-square diperoleh nilai $\mathrm{p}=0,048$ karena nilai $\mathrm{p}<0,05$ maka ada pengaruh ketepatan waktu terhadap kepuasan pasien.

Tabel 3: Analisis Multivariat Hasil Analisis Multivariat dengan Regresi Logistik Pengaruh Kualitas Pelayanan Kesehatan terhadap Kepuasan Pasien Peserta BPJS di Rumah Sakit Umum Daerah Haji Makassar Tahun 2018

\begin{tabular}{cllllll}
\hline Variabel & B & S.E & Wald & df & Sig. & Exp (B) \\
\hline Keterjangkauan/ akses & 1755 &, 664 & 5,503 & 1 &, 038 & 2,128 \\
Kenyamanan &, 243 &, 451 &, 292 & 1 &, 589 &, 784 \\
Ketepatan waktu & 1,185 &, 492 & 6,235 & 1 & $, 0,49$ & 1,191 \\
Constant & $-1,779$ & 1,341 & 7,208 & 1 &, 000 &, 092 \\
\hline
\end{tabular}

Sumber: Data Primer, 2018

\section{Analisis Multivariat}

Tabel 3 memperlihatkan bahwa variabel kualitas pelayanan yang sangat berpengaruh terhadap kepuasan pasien adalah dengan melihat nilai pengaruh $\operatorname{Exp}(B)$ yang paling tinggi ada pada variabel hubungan antar manusia sebesar 5.635 kali terhadap kepuasan pasien peserta BPJS di ruang rawat inap Rumah
Sakit Umum Daerah Haji Makassar dengan nilai $\mathrm{p}=0,030$.

\section{PEMBAHASAN}

Hasil penelitian ini menujukkan bahwa faktor keterjangkauan/akses $(p=0,039)$ dan ketepatan waktu $(p=0,048)$ berpengaruh secara signifikan terhadap kepuasan pasien peserta BPJS di RSUD Haji Makassar. Sedangkan faktor 
kenyamanan $(p=0,725)$ tidak berpengaruh secara signifikan terhadap kepuasan pasien peserta BPJS di RSUD Haji Makassar. Adapun dari hasil analisis multivariat dengan menggunakan uji regresi logistik berganda, variabel yang paling berpengaruh adalah keterjangkauan/ akses berganda dengan nilai $\operatorname{Exp}(B)$ sebesar 1.191 terhadap kepuasan pasien dengan nilai $\mathrm{p}=0,04$.

Akses terhadap layanan kesehatan artinya pelayanan kesehatan harus dapat dicapai oleh masyarakat, tidak terhalang oleh keadaan geografis, sosial, ekonomi, organisasi dan bahasa, lama dan biaya atau hambatan fisik lain yang dapat menghalangi seseorang untuk menerima layanan kesehatan Responden mengatakan akses baik karena merasa jarak yang ditempuh tidak begitu jauh menuju lokasi Rumah Sakit Umum Daerah Haji Makassar, kemudahan transportasi umum menuju rumah sakit, lokasi rumah sakit yang strategis, serta bahasa yang digunakan petugas kesehatan mudah dimengerti. Responden yang mengatakan akses kurang baik karena lokasi tempat tinggal yang jauh dari Rumah Sakit dan sulitnya transportasi bagi yang tidak memiliki kendaraan pribadi, serta jarak yang relatif jauh dari tempat tinggal responden dan memakan waktu yang tempuh yang lama untuk bisa sampai di rumah sakit.
Hal ini menunjukkan bahwa responden merasa puas karena dapat menjangkau dengan mudah rumah sakit tersebut, dengan transportasi umum. Semakin mudah akses/ terjangkau maka semakin tinggi kepuasan pasien. Pasien akan merasa lebih puas apabila akses untuk menuju rumah sakit lebih cepat. Sebaliknya apabila pasien merasa aspek keterjangkauan tidak baik, maka kepuasan mereka juga akan menurun.

Sebagaimana yang diungkapkan Pohan (2006) akses terhadap layanan kesehatan itu harus dapay dicapai oleh masyarakat tidak terhalang oleh keadaan geografis, sosial, ekonomi, organisasi dan bahasa. Akses bahasa artinya pasien harus dilayani dengan menggunakan bahasa atau dialek yang dapat dipahami oleh pasien.

Penelitian yang sama juga oleh Hamid R (2013) di Puskesmas Batua Kota Makassar dimana hasil penelitian menunjukkan $\mathrm{p}=0,00>0,05$ yang berarti bahwa ada hubungan yang signifikan antara variabel akses dengan kepuasan pasien.

Kenyamanan meliputi lingkungan fisik rumah sakit, penampilan petugas kesehatan, kebersihan ruangan perawatan, hal-hal yang membuat waktu tunggu lebih menyenangkan. Responden menyatakan nyaman terhadap penampilan petugas yang menarik dan bersih, kebersihan peralatan medis yang ada dalam ruangan perawatan. Responden menyatakan kurang nyaman 
terhadap kondisi ruang perawatan yang hanya satu kali dibersihkan setiap hari dan TV yang ada dalam ruang perawatan sudah rusak dan tidak diperbaiki.

Responden merasa kurang puas terhadap kenyamanan di RSUD Haji Makassar. Hal ini disebabkan oleh ruang perawatan yang kurang memadai, serta kondisi ruang perawatan yang kurang bersih, kloset pada kamar mandi yang sudah rusak dan tidak layak pakai, serta kasur yang tidak bagus. Sebagian responden merasa tidak puas dengan ketersediaan lahan parkir rumah sakit. Pasien yang datang kerumah sakit sebagian besar sulit mencari tempat untuk dapat memarkirkan mobil. Parkiran merupakan salah satu pendukung kualitas pela yanan. Ketersediaan parkiran dapat memberikan rasa nyaman kepada pasien, sehingga pasien dapat memanfaatkan fasilitas pelayan tersebut lagi.

Penelitian ini sejalan dengan penelitian yang dilakukan oleh Riswan (2013) yang menyatakan bahwa kenyamanan pelayanan tidak berpengaruh terhadap kualitas pelayanan di unit rawat inap RSUP Dr. Wahidin Sudirohusodo. Hasil penelitian menunjukkan keluhan pasien terkait kenyamanan pelayanan kurang disebabkan penerangan dalam ruangan kurang baik, kamar mandi tidak terjaga kebersihannya, keranjang sampah di ruangan tidak tersedia, ruang perawatan tidak tertata dengan rapi, air bersih yang susah diperoleh, alat medis dan alat makan kelihatan kurang bersih.

Juga beberapa keluhan penting dari pasien yang menjadi catatan pihak manajemen rumah sakit agar segera dibenahi untuk menjaga kenyamanan pasien saat dirawat seperti ventilasi udara yang sangat minim ditempat tersebut, tempat sampah yang kurang di setiap ruang perawatan, ruang perawatan yang hanya 1 kali dibersihakan setiap hari, tidak tersedia tempat sampah dalam ruangan perawatan.

Ketepatan waktu merupakan ketepatan perjanjian pelayanan kesehatan peserta BPJS, ketepatan waktu tunggu di loket pendaftaran, ketepatan jam buka pelayanan kesehatan, dan ketepatan waktu tunggu pemeriksaan kesehatan. Responden menyatakan baik terhadap ketepatan waktu karena ketepatan waktu buka dan tutup pelayanan, petugas tidak membuat pasien menunggu lama dalam menrima pelayanan kesehatan, pelayanan petugas yang tepat waktu dibagian administrasi. Sedangkan beberapa pasien menilai ketepatan waktu kurang baik, karena mereka harus menunggu sampai beberapa hari di ruang perawatan sebelum ditangani oleh dokter spesialis.

Hasil analisis menyatakan bahwa ada pengaruh ketepatan waktu terhadap kepuasan pasien BPJS. Responden merasa puas terhadap petugas rumah sakit yang tepat waktu pelayanan yang mereka dapatkan di bagian administrasi, bagian 
Laboratorium, maupun bagian apotik selalu tepat waktu, begitu juga dengan jam berkunjung/ jam pulang pengunjung yang selalu tepat waktu.

Penelitian ini sejalan dengan penelitian yang dilakukan oleh Jannah (2017)) yang menyatakan bahwa kecepatan waktu pendaftaran di RSGM Universitas Jember tergolong cepat. Kecepatan waktu pelayanan di RSGM Universitas Jember tergolong sedang dan mayoritas responden puas terhadap pelayanan di RSGM Universitas Jember. Hasil analisis data menunjukkan bahwa terdapat hubungan antara kecepatan waktu pelayanan terhadap kepuasan pasien di RSGM Universitas Jember.

Hasil penelitian yang dilakukan oleh Mukti (2013)) menunjukkan hal yang sama bahwa pasien yang puas terhadap petugas rumah sakit yang tepat waktu sebanyak $71(83.5 \%)$ orang hal ini dikarenakan pelayanan yang mereka dapatkan di bagian administrasi, bagian Laboratorium, maupun bagian apotik selalu tepat waktu, begitu juga dengan jam berkunjung/ jam pulang pengunjung yang selalu tepat waktu. Hasil uji statistik dengan menggunakan uji chi square diperoleh nilai $\mathrm{p}=0,002$, karena nilai $\mathrm{p}<$ 0,05 , hal ini berarti ada pengaruh ketepatan waktu terhadap kepuasan pasien.

Ketepatan waktu dan kecepatan waktu dari pelayanan yang diberikan oleh pemberi pelayanan dapat mencerminkan efektivitas kerja rumah sakit. Hal ini juga menyatakan bahwa pelayanan yang diberikan dapat diandalkan apabila sesuai dengan keinginan pasien berkaitan dengan kecepatan waktu pelayanan serta keakuratan dalam memberikan pelayanan yang akhirnya akan berdampak pada tercapainya kepuasan pasien.

\section{KESIMPULAN DAN SARAN}

Berdasarkan penelitian yang telah dilakukan hasil penelitian menunjukkan bahwa ada pengaruh keterjangkaun/ akses, ketepatan waktu dengan kepuasan pasien peserta BPJS. Hasil uji regresi logistik menunjukkan bahwa variabel ketepatan waktu yang mempunyai pengaruh paling besar terhadap kepuasan pasien peserta BPJS di Rumah Sakit Umum Daerah Haji Makassar. Pihak rumah sakit diharapkan meningkatkan dan memperbaiki sarana dan prasarana pada unit perawatan di ruang rawat inap. Pihak Rumah Sakit harus lebih meningkatkan kualitas pelayanan terutama pada pasien rawat inap dalam hal ketepatan waktu, keamanan, dan hubungan antar manusia agar kepuasan pasien lebih meningkat.

\section{DAFTAR PUSTAKA}

Hamid R. (2013). Hubungan Mutu Pelayanan Kesehatan dengan Kepuasan Pasien Rawat Jalan di Puskesmas Batua Makassar jurnal Administrasi dan Kebijakan Kesehatan (AKK) Fakultas 
Kesehatan Masyarakat Universitas Hasanuddin.

Istiqna. (2015). Harapan dan Kenyataan Pasien JKN terhadap Pelayanan Rawat Jalan Rumah Sakit Unhas. Jounal Media Kesehatan Masyarakat Indonesia, 11(4).

Jannah Alifah Nur, K., Ristya Widi E.Y. (2017). Hubungan Kecepatan Waktu Pelayanan terhadap Kepuasan Pasien di Rumah Sakit Gigi dan Mulut Universitas Jember. e-Jurnal Pustaka Kesehatan, 5(1).

Karyanto, J. A. (2015). Analisis Faktor yang Mempengaruhi Kepuasan Pasien Rawat Inap Peserta BPJS non PBI di Puskesmas Kabupaten donggala. Universitas Hasanuddin.

Kemenkes RI. (2014). Buku Pegangan Sosialisasi Jaminan Kesehatan Nasional (JKN) Dalam Sistem Jaminan Sosial Nasional. Jakarta.
Mukti Wibawani Yunestri, A. H., Mappeaty Nyoron. (2013).

Pengaruh Mutu Layanan Kesehatan Terhadap Kepuasan Pasien Rawat Inap Di Rumah Sakit Woodward Kota Palu. Jurnal AKK,, 2(3), 3541.

Pohan, I. S. (2006). Jaminan Mutu Layanan Kesehatan Dasar-Dasar pengertian dan Penerapan. Jakarta: ECG.

Profil RSUD Haji Makassar. (2017). Profil RSUD Haji Makassar Provinsi Sulawesi Selatan Tahun 2017. Makassar.

Supriyanto, e. (2010). Pemasaran Industri Jasa Kesehatan. Yogyakarta: ANDI.

Tjiptono, F. (2006). Prinsip Prinsip Total Quality Service Yogyakarta: ANDI.

WHO. (2011). Health System Financing; The Path to Universal Coverage. 